\title{
Morphological Variation of Rusty Crayfish Orconectes rusticus (Cambaridae) with Gender and Local Scale Spatial Gradients
}

\author{
Luke Etchison \\ Aquatic Biology and Fisheries Center \\ Department of Biology, Ball State University \\ 2000 W University Ave, Muncie, IN 47306, USA \\ Stephen J. Jacquemin (Corresponding author) \\ Aquatic Biology and Fisheries Center \\ Department of Biology, Ball State University \\ 2000 W University Ave, Muncie, IN 47306, USA \\ Tel: 1-740-815-2679 E-mail: sjjacquemin@bsu.edu
}

Michael Allen \& Mark Pyron

Aquatic Biology and Fisheries Center

Department of Biology, Ball State University

2000 W University Ave, Muncie, IN 47306, USA

Received: July 25, 2011

doi:10.5539/ijb.v4n1p163
Accepted: August 18, $2011 \quad$ Published: January 1, 2012

URL: http://dx.doi.org/10.5539/ijb.v4n1p163

\begin{abstract}
We tested for the influence of gender, stream, and urbanization on morphological variation in rusty crayfish (Orconectes rusticus) in an east-central Indiana, US watershed. We used geometric morphometrics to characterize shape and tested for differences among and within sites. Males had shallower rostrum, increased head width and length, decreased abdomen and cephalothorax width and length, and increased telson length compared to females. Morphology of males did not vary with stream or along an urban gradient. The morphology of females varied with stream and along an urban gradient. Female shapes from small creek sites were stouter and less fusiform than larger river specimens. Following an urban gradient, females exhibited an increasingly reduced abdominal and telson area and a more fusiform rostrum. Morphological variation is linked with adaptation and subsequent success of aquatic taxa. Disentangling the potential influences on crayfish morphology has implications for improved understanding of ecosystem structure and conservation.
\end{abstract}

Keywords: Aquatic ecology, Crayfish morphology, Geometric morphometrics, Environmental response, Sexual dimorphism

\section{Introduction}

Aquatic ecosystems are altered by anthropogenic impacts of urbanization, flow regulation, nutrient inputs, and habitat alteration (Dudgeon et al., 2006). However, the effects are not understood for most taxa (Folke et al., 1997; Paule et al., 2001; Perry et al., 2001). Success of aquatic organisms frequently varies with life history or functional traits (Frimpong and Angermeier, 2010). Trait variables frequently vary with environmental variation in predictable patterns (Schilderman et al., 1999; Hawkins et al., 2000). Organisms with generalist traits or morphological variation may be able to occupy a wider range of habitats (Haas et al., 2010; Langerhans et al., 2007). Morphological variation is an understudied explanatory mechanism of success in multiple habitat types of aquatic taxa (Dunithan et al., in press).

In North America, crayfish (Decapoda) play a vital role in freshwater ecosystems ranging from important food web consumers and prey, commercial fishery stock, and nutrient cycling (Taylor et al., 1996). It is estimated that 
48\% of the 338 known North American crayfish are currently extinct, endangered, special concern, or threatened. Among the greatest threats to native crayfish biodiversity is the widespread introduction and competition of rusty crayfish (Orconectes rusticus) with native taxa. Disentangling the factors implicit in the success of aquatic taxa is necessary to understand biodiversity and conservation implications.

The rusty crayfish is native to central North America and currently occupies a large geographic range relative to other crayfish taxa (Welch, 2006; Garvey and Stein, 1993). This species is characterized as an invasive and displaces native taxa (Olden et al., 2006) in part due to the exploitation of multiple habitats (Lodge et al., 2000). Improved understanding of morphological variation may elicit potential explanation of taxa distribution and local success (Minton et al., 2011). Morphological variation in aquatic taxa has been linked to habitat (Dunithan et al., in press) and gender (Taylor et al., 2010). However, information about morphological variation is currently unavailable for the majority of decapod taxa (but see Chambers et al., 1979; Dimmock et al., 2004; Taylor et al., 2010).

Our objectives were to test for rusty crayfish morphological variation 1) by gender, 2) among and within streams, and 3) along a single stream urban gradient. We hypothesized that rusty crayfish morphology would be affected by multiple factors and vary significantly with gender, stream, and urban gradient.

\section{Methods}

Individual $O$. rusticus were collected visually by hand at six sites in the White River watershed in Delaware County, Indiana, USA (Figure 1) in September 2010. We identified gender by presence / absence of modified swimmerets in males (Page, 1985). Collections were made in 2 systems; along a small creek and a medium sized river. Within stream (White River and Buck Creek) habitat among sites were of similar depth, flow conditions, substrate, and discharge. White River sites were further characterized by relative position to urban area (upstream, within town, downstream). This degree of 'urbanization' was calculated based on the presence and downstream accumulation of wastewater and runoff storm sewers (combined sewer overflows). This continuous measure of downstream urbanization paralleled river mile (drainage area), however, no tributaries existed in the study space and drainage area increased by less than 5\%. Thus, we considered the study area independent of river mile. We collected at each site until we had ten males (Form I) and females with total length ranges of $70-80 \mathrm{~mm}$ to reduce effects of allometry. Individuals were photographed with a Nikon D70 camera (Nikkor AF-S DX Macro Zoom Lens) with their dorsum toward the camera and overlaid on a scale.

We used geometric morphometric methodology for shape characterization (see Zelditch et al., 2004). All images were digitized by a single person (LE) using 17 landmarks (Figure 2) in tpsDig (Rohlf, 2001). Procrustes analysis was used to remove scaling, rotational, and translation bias prior to all shape analyses. Analyses were performed using MorphoJ (Klingenberg, 2008) and tpsRelw (Rohlf, 2010) and interpreted using thin plate spline deformation grids, which display directionality and degree of shape change (landmark configuration) relative to a mean consensus (Procrustes) shape. We tested for sexual dimorphism using a discriminant function analysis (DA) in MorphoJ software. Male and female shapes were characterized separately using relative warp analysis (RWA). Subsequent mean RWA scores were compared by stream (Buck Creek vs. White River) using two-sample t-tests separately for males and females. We tested mean RWA scores for urban impacts (White River sites only) by correlations with increasingly downstream sites (concurrent with increasing urban runoff and overflow). Alpha was set at 0.05 for all tests of significance.

\section{Results}

Discriminant function analysis indicated significant shape differences for males and females and successfully classified $87 \%$ of males and $90 \%$ of females (Mahalanobis distance $=2.18 ; T$-square $=142 ; p<0.0001$, Figure 3.). Males exhibited a shallower rostrum, increased head width and length, decreased abdomen and cephalothorax width and length, and increased telson length compared to females (Figure 3).

\subsection{Female crayfish morphology}

Relative warp analysis (RWA) for females explained $58 \%$ of the variation among individuals along three axes. RWA1 (eigenvalue 0.003 , Figure 4) explained $35 \%$ of variation and separated individuals by increased telson length, reduced cephalothorax area, reduced rostrum pronouncement, and increased abdominal area (positive loading individuals, Figure 5). RWA2 (eigenvalue 0.001 , Figure 4) explained $12 \%$ of variation and distinguished females by increased body width, reduced tail area, and increased abdominal area (positive loading individuals, Figure 5). RWA3 (eigenvalue 0.0001 ) explained $10 \%$ of variation and distinguished females by narrow anterior cephalothorax and decreased tail area (positive loading individuals). A significant trend of individuals exhibiting reduced telson length, increased cephalothorax area, increased rostrum pronouncement, and decreased 
abdominal area (negative RWA1 values) concurrent with increasing stream distance relative to the urban area was identified $(r=-0.40, p<0.013)$. Buck Creek and White River sites were not significantly different on RWA1. Females from smaller stream sites (Buck Creek) had significantly higher mean RWA2 scores and larger and increasingly stout body shape compared to females from the larger stream sites on the White River (two-sample t, $t_{32}=3.17, p<0.003$ ). RWA3 was not significantly differentiated by Buck Creek and White River classifications. However, RWA3 was significantly correlated with White River urbanization $(r=-0.30, p<0.07)$. Females that occurred at upstream sites had narrow cephalothorax and decreased tail area compared to females at downstream sites.

\subsection{Male crayfish morphology}

Relative warp analysis (RWA) for males explained $57 \%$ of the variation among individuals along three axes. RWA1 (eigenvalue 0.002 , Figure 6) explained $31 \%$ of variation and distinguished males based on increased width of anterior cephalothorax, increased cephalothorax area, shortened abdominal area, and decreased tail area (positive loading individuals, Figure 7). RWA2 (eigenvalue 0.0002, Figure 6) explained 13\% of variation and distinguished males based on increased cephalothorax area (positive loading individuals). RWA3 (eigenvalue 0.0001 ) explained $13 \%$ of the variation and distinguished males by a narrowing and extension of the abdominal and tail region (positive loading individuals). Mean male shape based on the RWA axes did not vary significantly with Buck Creek and White River classification or with increasing influence from an urban area.

\section{Discussion}

Our study is the first to our knowledge to quantify morphology in crayfish using geometric morphometrics. The covariation we identified for morphology and environmental variation may be expected given the success of this taxon in multiple habitat types. The rusty crayfish is an invasive species in a large proportion of the Mississippi River and Great Lakes basins (Olden et al., 2006). The ability to inhabit multiple habitat types that contain high environmental variation is a common trait for invasive taxa. We recommend that identification of high covariation of morphological and environmental variables may provide an additional criterion for identification of invasive taxa prior to their release into non-native ranges.

Male and female rusty crayfish morphology did not covary similarly with stream or urban river distance gradient. Other studies find similar differences in male and female morphological variation among sites. For example, Sint et al. (2005) found that male shape varied among populations but female variation was negligible for two European crayfish taxa. Pyron et al. (2007) found that female body shape varied with stream discharge and male body shape did not vary for a North American species of Cyprinidae. Female body shape may be the selected result of maximizing reproductive attributes in a given environment (Vanhooydonck et al., 2007). Although sexual dimorphism in shape may be partly the result of selection for increased fecundity in females, female rusty crayfish did not simply have larger abdomens or larger body size than males. Females appear to have increased morphological plasticity with environmental variation than males. An alternative hypothesis based on differences in male and female dispersal does not seem likely in rusty crayfish because male and female crayfish typically have similar movement patterns (Byron and Wilson, 2001). Differences in gender-specific morphological responses to environmental variation is expected to be from different selection pressures on males and females (Vanhooydonck et al., 2007) or different use of habitats, although there are few examples of males and females with different niches (Holmes, 1986). One gender may use morphology as a cue for mate quality or other reproductive indicator, but such behavior is unknown in crayfish.

Morphological variation among locations within the same species is typically a product of genetic variation and phenotypic plasticity (West-Eberhard, 1989). Our results of crayfish morphology that varies by steam locale (Buck Creek vs. White River) and increasing stream distance (White River) is similar to other stream taxa (Haas et al., 2010; Lande, 1980). Although we found significant differences within and among stream sites, identification of mechanisms and causation of the identified morphological variation will require common garden experiments combined with population genetics analyses. Morphological variation is typically a result of selection for phenotypes that provide energetic or functional advantages with local hydraulic variation (Pyron et al., 2007). However, the morphological gradient in crayfish we found among our White River sites does not fit a drainage based hydraulics hypothesis. Furthermore, our White River sites were distributed along a short stream distance that we predict is a single interbreeding crayfish population (Byron and Wilson, 2001).

The shape variation we identified from upstream to downstream of the urban area appears to be the result of a gradient in urban impacts and not drainage area. There are no stream confluences between the White River sites we selected, thus their drainage areas are nearly identical. We suggest that the White River morphological variation we identified that was correlated with stream distance is a result of increasing urban point and 
non-point source effluent (e.g., combined sewage overflow, surface runoff, and industrial discharge) in an urbanized region. This watershed is one of the most degraded watersheds in the country and contains, for example, ubiquitous organic compounds and synthetic pharmaceuticals (Bunch and Bernot, 2011).

Additional and more extensive field collections and habitat characterizations coupled with common garden experiments are necessary to further identify the mechanisms influencing shape variation in crayfish. Identification of causation will however, play a crucial role in disentangling the factors which determine populations and subsequent ecological communities.

\section{References}

Bunch, A.R., \& Bernot, M.J. (2011). Distribution of nonprescription pharmaceuticals in central Indiana streams and effects on sediment microbial activity. Ecotoxicology, 20, 97-109. http://dx.doi.org/10.1007/s10646-010-0560-6

Byron, C.J. \& Wilson, K.A. (2001). Rusty crayfish (Orconectes rusticus) movement within and between habitats in Trout Lake, Vilas County, Wisconsin. Journal of the North American Benthological Society, 20, 606-614. http://dx.doi.org/10.2307/1468091

Dimmock, A., Williamson, I., \& Mather, P.B. (2004). The influence of environment on the morphology of Macrobrachium australiense (Decapoda: Palaemonidae). Aquaculture International, 12, 435-456. http://dx.doi.org/10.1023/B:AQUI.0000042140.48340.c8

Dudgeon, D., Arthington, A.H., Gessner, M.O., et al. (2006). Freshwater biodiversity: importance, threats, status, and conservation challenges. Biological Reviews, 81, 163-182. http://dx.doi.org/10.1017/S1464793105006950

Dunithan, A., Jacquemin, S.J., \& Pyron, M. (In Press). Morphology of Elimia livescens (Mollusca) in Indiana, USA covaries with environmental variation. American Malacological Bulletin, 30.

Folke, C., Jansson, A., Larsson, J., \& Costanza, R. (1997). Ecosystem appropriation by cities. Ambio, 26, 167-172.

Frimpong, E.A., \& Angermeier, P.L. (2010). Trait-based approaches in the analysis of stream fish communities. In: Gido, K.B., \& D.A. Jackson (Eds.). Community Ecology of Stream Fishes: Concepts, Approaches, and Techniques (pp. 109-136). American Fisheries Society, Symposium 73, Bethesda, Maryland.

Garvey, J.E., \& Stein, R.A. (1993). Evaluating how chela size influences the invasion potential of an introduced crayfish (Orconectes rusticus). American Midland Naturalist, 129, 172-181. http://dx.doi.org/10.2307/2426446

Haas, T.C., Blum, M.J., \& Heins, D.C. (2010). Morphological responses of a stream fish to water impoundment. Biology Letters, 6, 803-806. http://dx.doi.org/10.1098/rsbl.2010.0401

Hawkins, C.P., Norris, R.H., Hogue, J.N., \& Feminella, J.W. (2000). Development and evaluation of predictive models for measuring the biological integrity of streams. Ecological Applications, 10, 1456-1477. http://dx.doi.org/10.1890/1051-0761(2000)010[1456:DAEOPM]2.0.CO;2

Holmes, R.T. (1986). Foraging patterns of forest birds: male-female differences. Wilson Bulletin, 98, 196-213, ids:C7300.

Klingenberg, C.P. (2008). MorphoJ. Faculty of Life Sciences. University of Manchester, UK. http://www.flywings.org.uk/MorphoJ_page.htm.

Lande, R. (1980). Sexual dimorphism, sexual selection, and adaptation in polygenic characters. Evolution, 34, 292-305. http://dx.doi.org/10.2307/2407393

Langerhans, R.B., Chapman, L.J., \& Dewitt, T.J. (2007). Complex phenotype-environment associations revealed in an East African cyprinid. Journal of Evolutionary Biology, 20, 1171-1181. http://dx.doi.org/10.1111/j.1420-9101.2007.01282.x

Lodge, D.M., Taylor, C.A., Hodich, D.M., \& Skurdal, J. (2000). Nonindigenous crayfishes threaten North American freshwater biodiversity: lessons from Europe. Fisheries, 25, 7-20. http://dx.doi.org/10.1007/s10530-005-7854-2

Minton, R.L., Lewis, E.M., Netherland, B., \& Hayes, D.M. (2011). Large differences over small distances: plasticity in the shells of Elimia potosiensis (Gastropoda: Pleuroceridae). International Journal of Biology, 3 , 23-32. 
Olden, J.D., McCarthy, J.M., Maxted, J.T., Fetzer, W.W., \& Van der Zanden, M.J. (2006). The rapid spread of rusty crayfish (Orconectes rusticus) with observations on native crayfish declines in Wisconsin (U.S.A.) over the past 130 years. Biological Invasions, 8, 1621-1628.

Page, L.M. (1985). The crayfishes and shrimps (Decapoda) of Illinois. Illinois Natural History Survey Bulletin, no. 33.

Paule, M.J., \& Meyer, J.L. (2001). Streams in the urban landscape. Annual Review of Ecology and Systematics, 32, 333-365. http://dx.doi.org/10.1146/annurev.ecolsys.32.081501.114040

Perry, W.L., Feder, J.L., \& Lodge, D.M. (2001). Implications of hybridization between introduced and resident $\begin{array}{lllll}\text { Orconectes } & \text { crayfishes. } & \text { Conservation } & \text { Biology, } & 15,\end{array}$ http://dx.doi.org/10.1046/j.1523-1739.2001.00019.x

Pyron, M., Fincel, M., \& Dang, M. (2007). Sexual size dimorphism and ecomorphology of spotfin shiner (Cyprinella spiloptera) from the Wabash River watershed. Journal of Freshwater Ecology, 22, 687-696. http://dx.doi.org/10.1080/02705060.2007.9664829

Rohlf, F. J. (2001). TpsDig - thin plate spline digitizer. version 2.11. State University of New York at Stony Brook, New York.

Rohlf, F. J. (2010). TpsRelw - thin plate spline relative warp analysis. version 1.49. State University of New York at Stony Brook, New York.

Schilderman, P.A.E.L., Moonen, E.J.C., Mass, L.M., Welle, I. \& Kleinjans, J.C.S. (1999). Use of crayfish in biomonitoring studies of environment pollution of the River Meusse. Ecotoxicology and Environmental Safety, 44, 241-252. http://dx.doi.org/10.1006/eesa.1999.1827

Sint, D., Dalla Via, J., \& Füreder, L. (2005). Morphological variations in Astacus astacus L. and Austropotamobius pallipes (Lereboullet) populations. Bulletin Française de la Pêche et de la Pisciculture, 376-377:637-652. http://dx.doi.org/10.1051/kmae:2005021

Taylor, C.A., Warren Jr., M.L., Fitzpatrick Jr., J.F., Hobs III, H.H., Jezerinac, R.F., Pflieger, W.L., Robison, W.L. (1996). Conservation status of crayfishes of the United States and Canada. Fisheries, 21, 25-38.

Taylor, M.S., Blechle, B.E., \& Pobst, B.S. 2010. Morphological divergence between cave and surface populations of the digger crayfish, Fallicambarus fodiens (Cottle, 1863) (Decapoda, Cambaridae). Crustaceana, 83, 1303-1313. http://dx.doi.org/10.1163/001121610X535555

Vanhooydonck, B., Herrel, A., \& Irschick, D.J. (2007). Determinants of sexual differences in escape behavior in lizards of the genus Anolis: a comparative approach. Integrative and Comparative Biology, 47, 200-210. http://dx.doi.org/10.1093/icb/icm018

Welch, S.M., \& Eversole, A.G. (2006). Comparison of two burrowing crayfish trapping methods. Southeastern Naturalist, 5, 27-30. http://dx.doi.org/10.1656/1528-7092(2006)5[27:COTBCT]2.0.CO;2

West-Eberhard, M.J. (1989). Phenotypic plasticity and the origins of diversity. Annual Review of Ecology and Systematics, 20, 249-278. http://dx.doi.org/10.1146/annurev.ecolsys.20.1.249

Zelditch, M. L., Swiderski, D.L., Sheets, H.D., \& Fink, W.L. (2004). Geometric morphometrics for biologists: a primer. Elsevier Academic Press, London. 


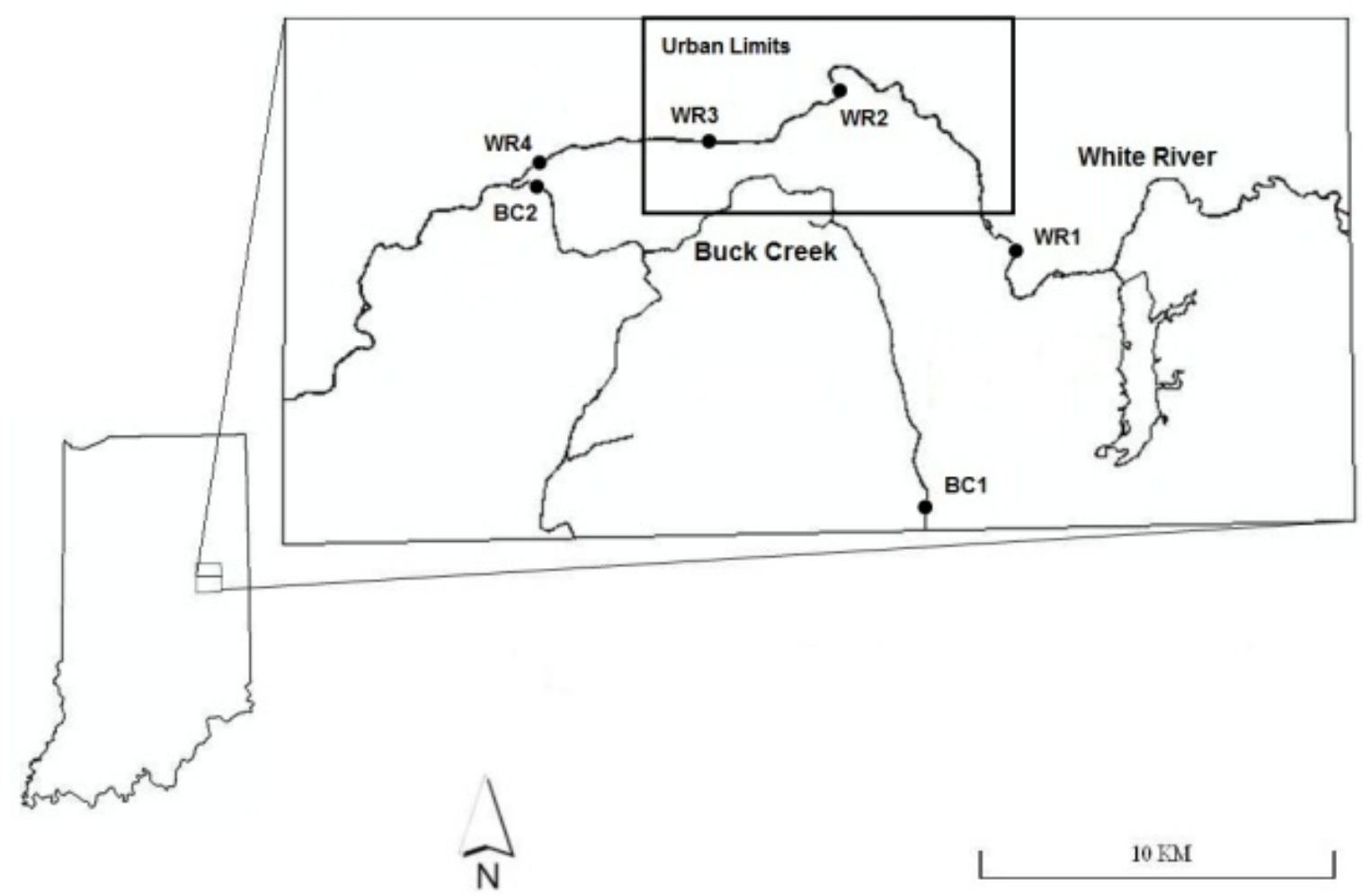

Figure 1. Map of site locations in Delaware County, Indiana, USA with stream names and the area of urban impacts in a box

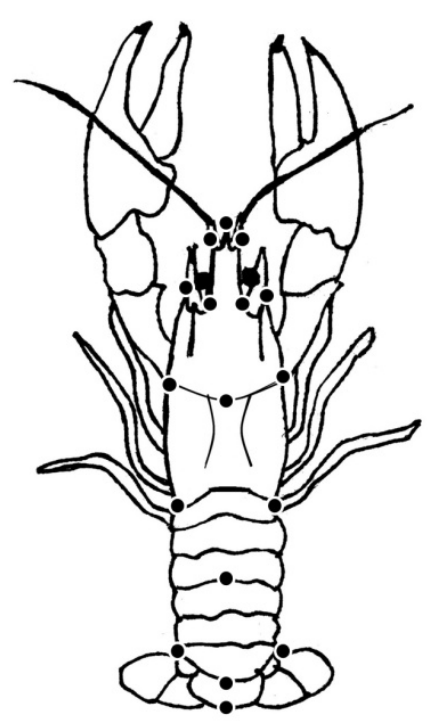

Figure 2. Consensus image with body landmark placement

Landmarks indicate acumen of rostrum, right marginal spine, right suborbital angle origin, right antennal spine, right cervical spine, right abdominal carapace junction, anterior edge of right uropod, median of telson posterior, anterior edge of uropod, left abdominal carapace junction, left cervical spine, left antennal spine, left suborbital angle origin, left marginal spine, median of cervical groove, median of $3^{\text {rd }}$ abdominal junction, and median of telson anterior. 


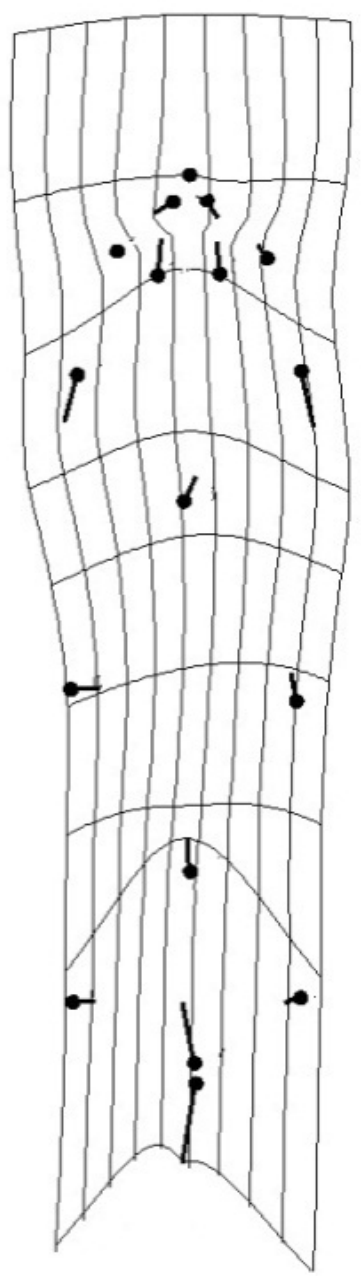

Figure 3. Discriminant analysis deformation grid. Vectors indicate direction and relative amount of change from female to male individuals. Scaling factor of 10 shown

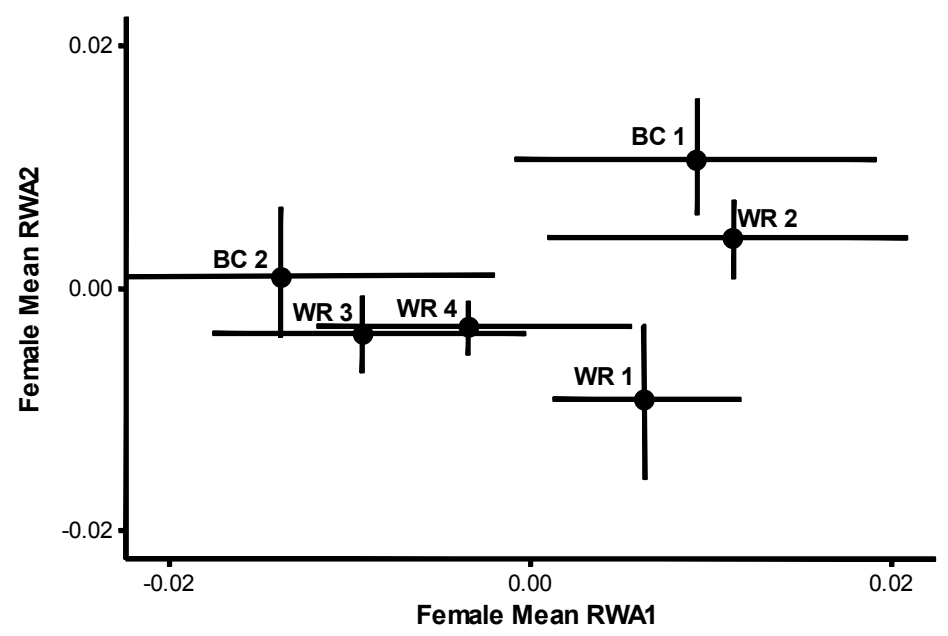

Figure 4. Mean relative warp analysis site scores and 95\% confidence intervals for female Orconectes rusticus. See Figure 1 for site abbreviations 

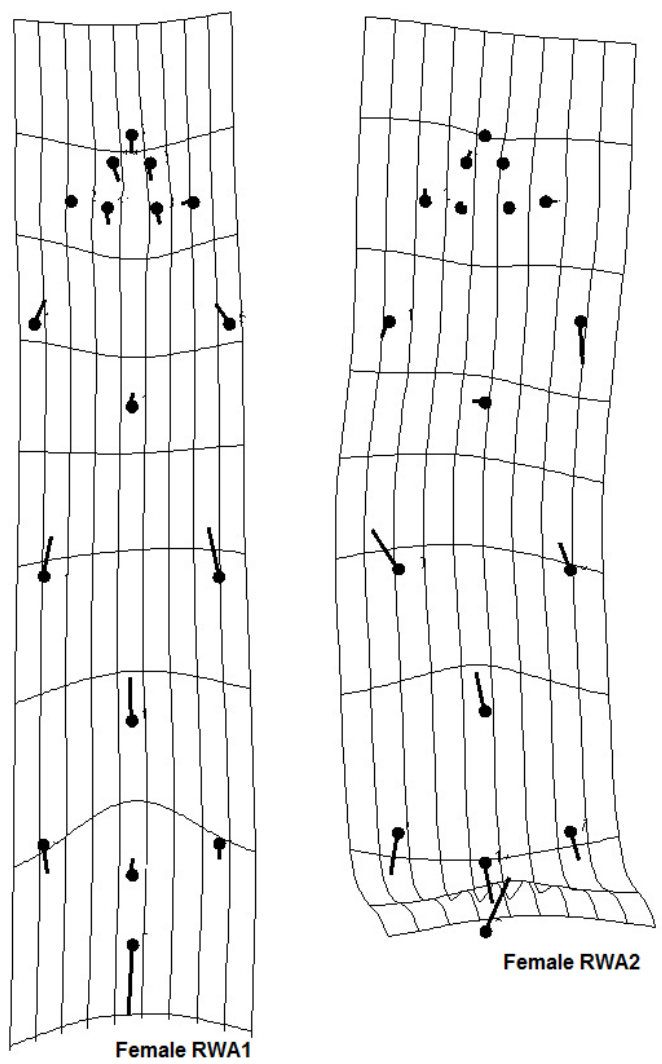

Figure 5. Relative warp analysis (positive loadings) deformation grids for female Orconectes rusticus

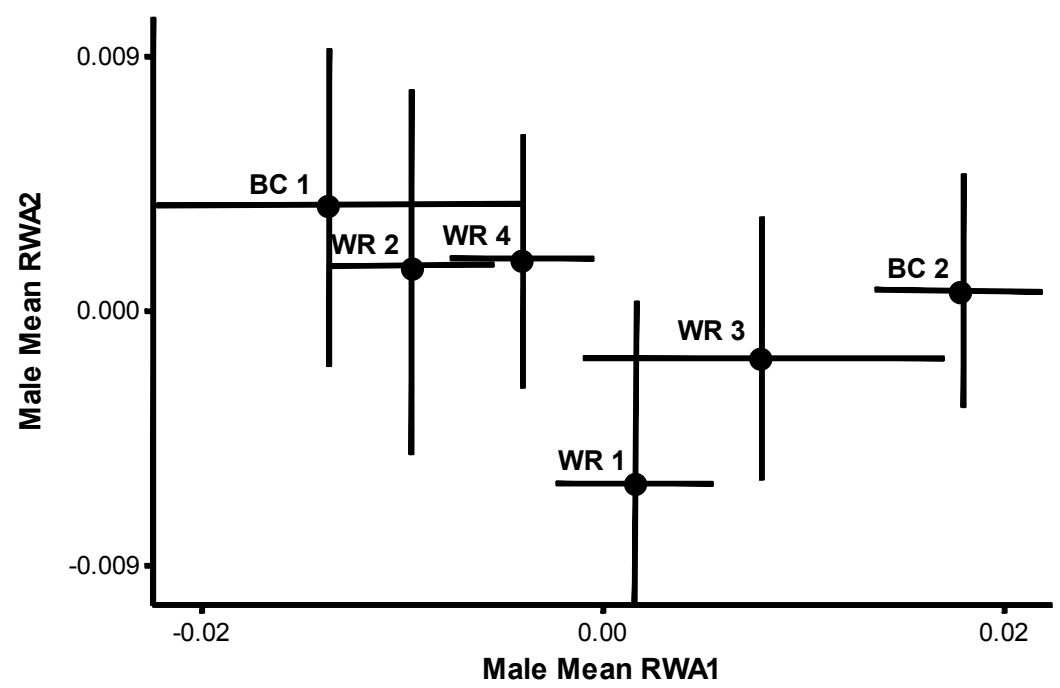

Figure 6. Mean relative warp analysis site scores and $95 \%$ confidence intervals for male Orconectes rusticus. See Figure 1 for site abbreviations 


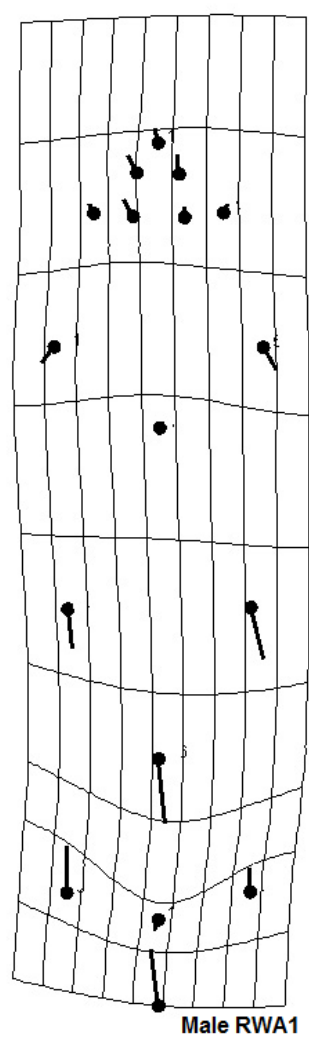

Figure 7. Relative warp analysis (positive loadings) deformation grids for male Orconectes rusticus 